\title{
Historical Perspective of the Addition of Magnetic Nanoparticles Into Anaerobic Digesters (2014-2021)
}

\author{
Eudald Casals ${ }^{1}$, Raquel Barrena ${ }^{2 *}$, Edgar Gonzalez ${ }^{3}$, Xavier Font $^{2}$, Antoni Sánchez $^{2}$ and \\ Victor Puntes ${ }^{4}$ \\ ${ }^{1}$ School of Biotechnology and Health Sciences, Wuyi University, Jiangmen, China, ${ }^{2}$ GICOM Research Group Department of \\ Chemical, Biological and Environmental Engineering, Universitat Autònoma de Barcelona Edifici Q, Carrer de Les Sitges Bellaterra \\ (Cerdanyola Del Vallès), Barcelona, Spain, ${ }^{3}$ Universidad Javeriana, Facultad de Ingenieria, Grupo de Nanociencia y \\ Nanotecnologia, Bogotá, Colombia, ${ }^{4}$ Institut Català de Nanosciència I Nanotecnologia (ICN2), Bellaterra, Barcelona, Spain
}

OPEN ACCESS

Edited by:

Eugénio Campos Ferreira, University of Minho, Portugal

Reviewed by: Luciana Ribeiro Pereira, University of Minho, Portugal

Federico Aulenta,

Water Research Institute, Italy

*Correspondence: Raquel Barrena raquel.barrena@uab.cat

Specialty section:

This article was submitted to Environmental Chemical Engineering, a section of the journal Frontiers in Chemical Engineering

Received: 22 July 2021 Accepted: 08 November 2021 Published: 26 November 2021

Citation:

Casals E, Barrena R, Gonzalez E, Font X, Sánchez A and Puntes V (2021) Historical Perspective of the Addition of Magnetic Nanoparticles Into Anaerobic

Digesters (2014-2021).

Front. Chem. Eng. 3:745610.

doi: 10.3389/fceng.2021.745610
The addition of magnetic nanoparticles to batch anaerobic digestion was first reported in 2014. Afterwards, the number of works dealing with this subject has been increasing year by year. The discovery of the enhancement of anaerobic digestion by adding iron-based nanoparticles has created a multidisciplinary emerging research field. As a consequence, in the last years, great efforts have been made to understand the enhancement mechanisms by which magnetic nanoparticles (NPs) addition enhances the anaerobic digestion process of numerous organic wastes. Some hypotheses point to the dissolution of iron as essential iron for anaerobic digestion development, and the state of oxidation of iron NPs that can reduce organic matter to methane. The evolution and trends of this novel topic are discussed in this manuscript. Perspectives on the needed works on this topic are also presented.

Keywords: iron nanoparticles, biogas, enhancement mechanisms, magnetite, anerobic digestion

\section{HIGHLIGHTS}

- Magnetite nanoparticles produce significant improvements in anaerobic digestion.

- Enhancement mechanisms are still not clear despite the increase of research.

- Iron supplemententation and iron state of oxidation are proposed as mechanisms.

- Iron nanoparticle properties and microbiota complexity are the key issues.

\section{INTRODUCTION}

In 2014, two independent groups reported enhancing anaerobic organic waste processing by adding iron oxide nanoparticles (NPs) (Casals et al., 2014; Cruz Viggi et al., 2014). Iron NPs usually are made of zero valent iron $\left(\mathrm{Fe}\right.$ ), partially oxidized iron (magnetite, $\mathrm{Fe}_{3} \mathrm{O}_{4}$ ), totally oxidized iron (maghemite or hematite, $\mathrm{Fe}_{2} \mathrm{O}_{3}$ ), and iron oxide-hydroxide (ferrihydrite, $\mathrm{FeOOH}$ ). $\mathrm{Fe}$ and $\mathrm{Fe}_{3} \mathrm{O}_{4}$ are both conductive and result in a more stable suspension than the other forms, insulators or semiconductors. In the first work, Casals et al. (2014) reported the increase in the production of biogas when adding magnetite NPs (in batch, with digested sewage sludge as inoculum, and cellulose as substrate) while in the second work, 2 months later, Cruz Viggi et al. (2014) showed how ironbased NPs accelerated methanogenesis (which was translated into an increase of production of methane in practical terms). In both cases, the amount of employed iron was minimal, and the effects 


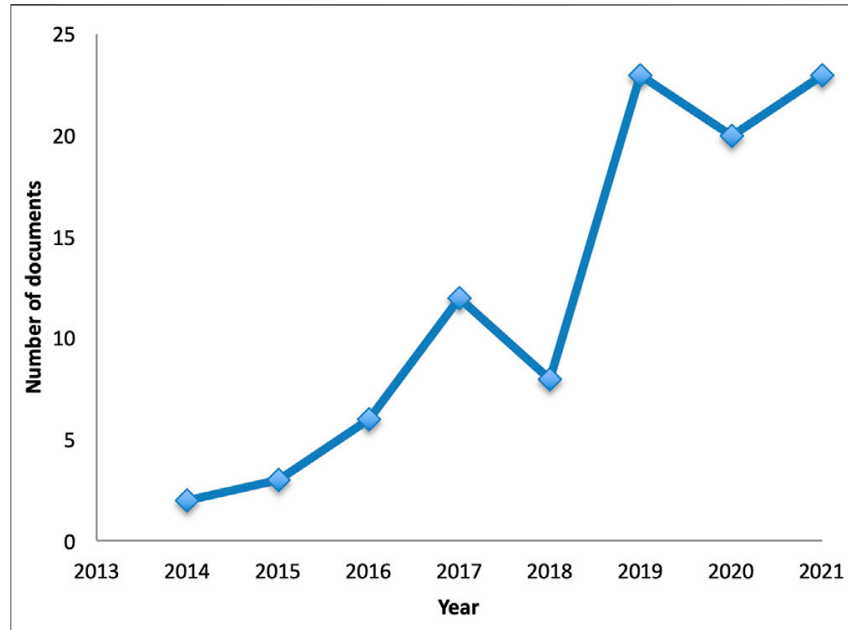

FIGURE 1 | Scientific works by year studying the effects of iron-based nanoparticles on anaerobic digestion (keywords of the search: iron nanoparticles AND anaerobic digestion. Source: Scopus ${ }^{\circledR}$, Elsevier).

were superior to adding only ionic iron. Under these conditions, the results of Casals et al. (2014) were attributed to the corrosion and disintegration of the iron oxide NPs providing sufficient amounts of essential iron needed for microbial proliferation, in an analogy to Feromuxytol, a solution of iron oxide NPs for intravenous administration that the FDA approved to treat iron deficiency anemia (Schwenk et al., 2010). Iron plays a key role in several processes of anaerobic microorganisms and has been used as an additive in anaerobic digestion (Romero-Güiza et al., 2016). In the second case, the effect was attributed to a "catalytic" phenomenon where NPs act as electron conductors between organic matter and microbes to reduce carbon. This latter hypothesis is challenged because insulating NPs (different iron oxide) did not provide any enhancement in anaerobic digestion. In the original hypothesis, the observed other effects produced by different iron-based NPs were not due to their different conductivity but their different solubility, which depends on the crystal structure, nanoparticle size, shape, and surface state. Casals et al. (2014) conducted a detailed study on all the relevant physicochemical characteristics of magnetite NPs. Previously, the same authors (Barrena et al., 2009) have demonstrated that magnetic iron-based NPs showed no toxicity in a large variety of environmental toxicity tests.

\section{Trends of the Emerging Topic}

Since then, the number of scientific works describing enhancing anaerobic digestion by the provision of iron-based NPs is exponentially increasing (Figure 1). In a following work, Yang et al. (2015) showed that magnetite addition significantly accelerated methane production from acetate in a doseindependent manner. This indicated its catalytic (or essential nutrient) contribution of the NPs to the process, then amplified by biology, probably re-shaping the microbiome. Results from high-throughput sequencing analysis revealed that Rhodocyclaceae-related species were selectively enriched, which were likely the key players for converting acetate to methane. Compared to the paddy soil enrichments obtained in the absence of magnetite, the maximum methane production rate was significantly higher (1.5-5.5 times higher for the artificial medium and 0.2-1.7 times higher for the effluents). That magnetite additives provided a suitable environment for methanogens was also confirmed the same year (Liu et al., 2015).

In the same year, the hypothesis of NPs as electrodes was again described. Particles of conductive iron oxides (e.g., magnetite) are known to facilitate microbial interspecies electron transfer (termed as electric syntrophy). Electric syntrophy has been reported to enhance the methanogenic degradation of organic acids by mesophilic communities in soil and anaerobic digesters (Yamada et al., 2015). In this work, supplementation of magnetite accelerated methanogenesis from acetate and propionate under thermophilic conditions, while ferrihydrite supplementation also accelerated methanogenesis from propionate. Microbial community analysis revealed that supplementation of magnetite drastically changed bacterial populations in the methanogenic acetate-degrading cultures, in which Tepidoanaerobacter sp. and Coprothermobacter sp. dominated (Yamada et al., 2015). Again, the fact that similar effects were observed with non-conducting NPs complicated the electron transfer hypothesis, while the increased performance of magnetite could be because of its higher dispersion and possibility of realsing iron ions (Casals et al., 2014), not electrical conductivity, or at least not exclusively. Similar results were observed on the anaerobic digestion of dairy wastewater in a batch mode (Baek et al., 2015). In this work, reactors supplemented with ferric oxyhydroxide (R2), and magnetite (R3) showed significantly enhanced biomethanation performance when compared with the control (R1). The removal of chemical oxygen demand (COD) after 30 days was 31.9, 59.3, and $82.5 \%$ in R1, R2, and R3, respectively. The consumed COD was almost fully recovered as biogas in R2 and R3, while only 79\% was recovered in R1. The total energy production as biogas was accordingly $32.2,71.0$, and $97.7 \mathrm{~kJ}$ in $\mathrm{R} 1, \mathrm{R} 2$, and $\mathrm{R} 3$, respectively. The reactors also differed in the acid formation profile with more propionate and butyrate found in $\mathrm{R} 1$, and more acetate found in R3. The enhanced biomethanation was associated with variations in the bacterial community structure, supposedly induced by the ferric oxides added. In contrast, no evident variation was observed in the microbial community structure among the reactors.

Curiously, only Casals et al. (2014) analyzed the state of iron after digestion, observing a progressive degradation and disintegration of the added NPs. Unfortunately, most of the paper dealing with anaerobic digestion amended with NPs ignore the effects of these materials one released and dispersed on the environment as a fertiliser and its potential associated risks. In general some reports on the fate of magnetite NPs in the environment shown how they tend to slowly dissolve (Cheng et al., 2018).

In 2016, the first review article on understanding bioenergy production and optimization at the nanoscale, including the observations with iron-based NPs, was released. Their extensive literature review indicated that anaerobic digestion process in sludge can be enhanced using magnetite 
nanoparticles, giving higher methane yields (Rahman et al., 2016). Also in 2016, different nanotechnologies were combined, like supporting magnetite NPs in carbon nanotube fibers, graphite, graphene, and activated carbon, reporting significant enhancements (Zhang et al., 2018).

\section{First Continuous Experiments and Long-Term Effects Studies on Magnetite Supplementation}

In 2016, the first study of the use of magnetite NPs in continuous reactors appeared (Vecchia et al., 2016). In particular, this study examined the effect of magnetite nanoparticles supplementation on the methanogenic conversion of organic substrates, both in batch trials using pure compounds (i.e., propionate and butyrate) and in continuous regime trials using real food waste as substrate. Batch experiments demonstrated the validity of the proposed approach once again, whereby the conductive particles were supposed to promote the occurrence of direct interspecies electron transfer processes between acetogens and methanogens. Notably, continuous experiments confirmed the significance of this approach for treating real substrates, although the relative magnitude of the stimulatory effect was slightly lower.

In 2017, the addition of small doses $\left(20 \mathrm{mg} \mathrm{L}^{-1}\right)$ of Fe NPs and $\mathrm{Fe}_{3} \mathrm{O}_{4}$ magnetic NPs to pig-manure significantly increased (1.45 and 1.66 times) the biogas volume produced by the control (Abdelsalam et al., 2017). Moreover, the additives above increased dramatically by 1.59 and 1.96 times the methane volume produced by the control (Abdelsalam et al., 2017). Similar benefits at similar doses were observed when codigesting pig manure and wheat straw (Wang et al., 2017). The same year, a very interesting study appeared where authors studied the long-term effects of magnetite supplementation in the continuous anaerobic digestion regime of a dairy effluent (Baek et al., 2017). The same authors also reported indirect benefits of the magnetite addition in process performance, such as increased process resilience and stability (Baek et al., 2017). Interestingly, in line with the added benefits in addition to enhanced biogas production, the authors observed the robustness of the system against acidification (non published data), or high ammonia concentration (as a consequence of too much nitrogen reduction) (Zhuang et al., 2018).

\section{Following Works Trying to Understand the Mechanisms Involved in Biogas Enhancement}

Uncovering underlying mechanisms is necessary to exploit these phenomena for society. This is why works trying to understand fundamental mechanisms of the enhancement of anaerobic digestion by iron-based NPs have also been increasing since little after its discovery. Microbiological systems' complexity, their acclimation times, proliferation, and phenotype expressions, have to be understood under the exposure to different forms and doses of iron oxide NPs, often superparamagnetic, conductive, and catalyst. Conductive materials have been widely investigated to accelerate and decreases the oscilation typicaly found in the conversion of organic waste to methane. However, the potential mechanisms involved with different types of conductive materials are still unclear. Magnetite and granular activated carbon (GAC), as typical conductive materials, were respectively supplemented to acidogenesis and methanogenesis processes on a two-phase anaerobic digestion system, in an attempt to explore their mechanism of action (Zhao et al., 2017). The results showed that magnetite supplemented to the acidogenic phase enhanced the decomposition of complex organic molecules into simple ones and significantly raised the hydrogen partial pressure, as well as enriched the hydrogen-utilizing methanogens. This was not expected for aceticlastic methanogenesis, known as a mainstream of methanogenesis in most traditional digesters. GAC supplemented to the methanogenic phase had less influence on syntrophic metabolization of alcohols and fatty acids, indicating that direct interspecies electron transfer (DIET) could not fully account for the observed effects.

More specific wastes were also treated with magnetite, as organic solvents (Leitão et al., 2018). The addition of NP (170 $\mathrm{mg} \mathrm{L}^{-1}$ total $\mathrm{Fe}$ ) enhanced the acetate-driven reductive dechlorination of 1,2-dichloroethane to harmless ethene up to 3.3-times, while decreasing the lag time by 0.8 times ( 23 days) when compared to unamended (magnetite-free) controls. Dechlorination activity was correlated with the abundance of Dehalococcoides mccartyi, which accounted up to $50 \%$ of total bacteria, pointing to a key role of this microorganism in the process. Similar results were obtained for ciprofloxacin (Yang et al., 2017). Beneficial effects were also observed in the treatment of the Organic Fraction of Municipal Solid Waste (OFMSW) (Qin et al., 2017). During this year, one of the works postulated on the effects of magnetite NPs absorbing other cations, such as $\mathrm{Cu}$ or Zn (Liang et al., 2017).

The year 2017 ended with a publication on the possible effects of $\mathrm{Fe}_{3} \mathrm{O}_{4}$ on the different microbial species in the anaerobic consortia, searching for DIET effects that could not entirely describe observations (as the enhancement of biogas production with no conductive iron oxides or the nonenhancement with conductive activated carbon (vide supra) (Zhao et al., 2018a). 2018 started with more studies into magnetite roles in the improvement of anaerobic sludge digestion observing modifications of the microbial populations correlated to the increased biogas production (Peng et al., 2018). An interesting work presented kinetic modeling for bioaugmented anaerobic digestion of the OFMSW by using $\mathrm{Fe}_{3} \mathrm{O}_{4}$ nanoparticles were more than $50 \%$ of the volatile solid reduction was achieved with the addition of $75 \mathrm{mg} \mathrm{L}^{-1} \mathrm{Fe}_{3} \mathrm{O}_{4}$ NPs (Ali et al., 2018). It was also in 2018 when the original hypothesis was recovered, and the enhancement of methane production by Methanosarcina barkeri using $\mathrm{Fe}_{3} \mathrm{O}_{4}$ nanoparticles, as an iron sustained release agent, was reported (Chen et al., 2018a). Other hypotheses point that responsible for methane improvement is not only the presence of iron but its state of oxidation, with can happen with magnetite but it is more evident when using zero valent iron NPs which is the most reduced oxidation state of iron. In this case, the effect of the reduction of organic matter to methane has been observed when using materials such as 
wastewater sludge (Barrena et al., 2021) and pig manure (Cerrillo et al., 2021). These studies highlight the iron state of oxidation as a key role in the enhancement of methane in the anaerobic digestion process, even at thermophilic conditions.

\section{Results Using Wastes From the Different Feedstock}

Since then, other wastes were explored, and the observed biogas production enhancement when exposed to ironbased NPs reported. This includes poultry litter (Hassanein et al., 2019), cattle manure (Abdelwahab et al., 2020), glycerol (Im et al., 2019), fresh leachate from a municipal solid waste incineration plant (Lei et al., 2018), canola straw, and banana plant wastes with buffalo dung (Noonari et al., 2019), and microalgal biomass (Zaidi et al., 2018). At the same time, other iron oxidation states were proposed, without notable improvements with respect to magnetite (Chen et al., 2018b), while exploration on the fundamental mechanisms persisted, including now the possibility of NP dissolution, since a significant $\mathrm{Fe}^{2+}$ concentration was detected in the aqueous phase after use of $\mathrm{Fe}_{3} \mathrm{O}_{4} \mathrm{NPs}$ (Zhao et al., 2018b). In 2019 the enhancement of anaerobic digestion was studied as a method for disinfection and the elimination of antibiotic resistance genes (Xiang et al., 2019; Zhang et al., 2019a; Zhang et al., 2019b), thanks to augmented digestion of the substrate, other added benefit of enhancing biogas production. Since then, a number of tests with positive results in different substrates have been reported, including chicken litter (Aguilar-Moreno et al., 2020), sugar beet waste (Beiki and Keramati, 2019), acetate, propionate, and butyrate under ammonia stressed condition (Lee et al., 2019), phenol (He et al., 2019) and tribromophenol (under microaerobic conditions) (Yang et al., 2019). However the reader should take into account that number of conditions, concentrations of NPs and mode of operation (continuous, semicontinuous or batch) is very large and makes it difficult to interpret and compare results from differents studies.

\section{Understanding the Enhancement Mechanisms by Magnetic NPs Addition}

Extensive work has been dedicated to understanding the mechanisms involved in the enhancement of anaerobic digestion using iron-based NPs. Considering that NPs work at relatively low doses (in oder of magnitude of ppm), this indicates an essential nutrient or catalytic effect, together with a biological amplification. Initially, the studies focused on which microbial colonies were modified by the exposure of iron-based NPs to anaerobic digestion (Wang et al., 2016). Currently, as new details of how it works are revealed, the focus is still on the potential contribution of iron NPs to electron transfer activities, as if the addition of a dispersion of conductive NPs will create a chemical environment that promotes the redox processes in which organic matter is degraded towards the production of biogas (Wang et al., 2018; Fu et al., 2019; Jin et al., 2019; Li et al., 2019; Liu et al., 2019; Namal, 2019; Song et al., 2019; Y., Wang et al., 2019a; Zhang et al., 2019). What is undoubtedly clear is that electro-redox activities are increased when iron NPs are present.

With time, the iron oxide NPs have been derived (Ali et al., 2019), and the process has been sophisticated. For example, it has been observed the synergistic effect of alkaline pre-treatment and magnetite NPs application on biogas production from rice straw (Khalid et al., 2019). Similarly, a short-term stimulation of ethanol enhanced the magnetite effect on anaerobic digestion (Wang et al., 2019b). Besides, the use of the magnetic moment of iron-based NPs has been exploited for recycling these NPs, which is always a matter of interest for safety and efficiency (Ren et al., 2019). However, in the dissolution hypothesis, by adequately (low) dosing the digestors, in analogy with the human drug (Feromuxytol), the provided magnetite is consumed during the process before the next doses are needed, avoiding the need of recycling and the dispersion of NPs into the environment (Casals et al., 2014). During 2019, several reviews on the subject were published (Abdelsalam and Samer, 2019; Baniamerian et al., 2019; Dehhaghi et al., 2019) while today current activity continues introducing different magnetic NPs in different specific anaerobic process (Aguilar-Moreno et al., 2020).

Summarizing, it is clear that iron-based NPs at doses of $\mathrm{mgL}^{-1}$ have significant improvements of all aspects of anaerobic digestion: up to 5.5 times increased biogas production together with increased production rate, stability, robustness, disinfection, and reproducibility. Many different types of iron-based NPs have been shown to produce such increase, being small non-aggregated magnetite NPs probably the most efficient species up to date. The underlying mechanism is unclear. It has been observed recurrently that the provision of mineral iron (in many different forms) modifies the microbial populations and increases methanization. There are two current hypotheses, one on the conductivity of magnetite NPs, based on the wellknown electron transfer between microbial cells and minerals. However, this hypothesis gets challenged when non-magnetic iron oxide NPs also increases biogas production while other non-iron conductive nanomaterials barely increase biogas production. Besides, there is the iron dosing hypothesis, which consists on the progressive dissolution of the iron oxide NPs to provide this essential nutrient in the form of $\mathrm{Fe}^{2+}$, depending on the chemistry of the waste, the presence of iron, of siderophores, redox conditions, and the NP crystal structure, size, shape and surface state of the employed NPs. Note that providing iron ions in a sustained way is different from providing directly the same amount of iron in the ionic form. $\mathrm{Fe}^{2+}$ is very reactive and short-lived; therefore, a single dose may be too aggressive while its effect is acute (short in time). By providing the iron in an unstable mineral form, it slowly degrades, providing a stable iron-enriched environment from where microbial cells can take advantage. The dosing as NPs has other benefits in these two cases; the NPs can first homogeneously distribute after injection into an anaerobic (close system) before providing its constituents. Due to the slow kinetics of NP dissolution, the 
introduced dose can be relatively high, in such a way that chronic treatment is provided with a single dose.

\section{CONCLUSION}

- Although not yet predictable, particulate mineral iron enhancement of anaerobic digestion seems to work everywhere. Magnetic nanoparticles produced an enhament of anaerobic digestion of different substrates being the most important the increase of the production of methane.

- Among the mechanisms proposed for the enhancement of anaerobic digestion using iron nanoparticles several trends have been studied: iron as an essential element for anaerobic digestion, iron state of oxidation of nanoparticles and change in the microbial community due to iron supplementation.

\section{REFERENCES}

Abdelsalam, E. M., and Samer, M. (2019). Biostimulation of Anaerobic Digestion Using Nanomaterials for Increasing Biogas Production. Rev. Environ. Sci. Biotechnol. 18, 525-541. doi:10.1007/s11157-019-09505-0

Abdelsalam, E., Samer, M., Attia, Y. A., Abdel-Hadi, M. A., Hassan, H. E., and Badr, Y. (2017). Influence of Zero Valent Iron Nanoparticles and Magnetic Iron Oxide Nanoparticles on Biogas and Methane Production from Anaerobic Digestion of Manure. Energy 120, 842-853. doi:10.1016/j.energy.2016.11.137

Abdelwahab, T. A. M., Mohanty, M. K., Sahoo, P. K., and Behera, D. (2020). Impact of Iron Nanoparticles on Biogas Production and Effluent Chemical Composition from Anaerobic Digestion of Cattle Manure. Biomass Conv. Bioref.. doi:10.1007/S13399-020-00985-7

Aguilar-Moreno, G. S., Navarro-Cerón, E., Velázquez-Hernández, A., HernándezEugenio, G., Aguilar-Méndez, M. Á., and Espinosa-Solares, T. (2020). Enhancing Methane Yield of Chicken Litter in Anaerobic Digestion Using Magnetite Nanoparticles. Renew. Energ. 147, 204-213. doi:10.1016/ j.renene.2019.08.111

Ali, A., Mahar, R. B., Abdelsalam, E. M., and Sherazi, S. T. H. (2018). Kinetic Modeling for Bioaugmented Anaerobic Digestion of the Organic Fraction of Municipal Solid Waste by Using Fe3O4 Nanoparticles. Waste Biomass Valor. 10, 3213-3224. doi:10.1007/s12649-018-0375-x

Ali, A., Mahar, R. B., and Sherazi, S. T. H. (2019). Methane Augmentation of Anaerobic Digestion of Food Waste in the Presence of Fe3O4 and Carbamide Capped Fe3O4 Nanoparticles. Waste Biomass Valor. 11, 4093-4107. doi:10.1007/s12649-019-00732-8

Baek, G., Jung, H., Kim, J., and Lee, C. (2017). A Long-Term Study on the Effect of Magnetite Supplementation in Continuous Anaerobic Digestion of Dairy Effluent - Magnetic Separation and Recycling of Magnetite. Bioresour. Technol. 241, 830-840. doi:10.1016/j.biortech.2017.06.018

Baek, G., Kim, J., Cho, K., Bae, H., and Lee, C. (2015). The Biostimulation of Anaerobic Digestion with (Semi)conductive Ferric Oxides: Their Potential for Enhanced Biomethanation. Appl. Microbiol. Biotechnol. 99, 10355-10366. doi:10.1007/s00253-015-6900-y

Baniamerian, H., Isfahani, P. G., Tsapekos, P., Alvarado-Morales, M., Shahrokhi, M., Vossoughi, M., et al. (2019). Application of Nano-Structured Materials in Anaerobic Digestion: Current Status and Perspectives. Chemosphere 229, 188-199. doi:10.1016/j.chemosphere.2019.04.193

Barrena, R., Casals, E., Colón, J., Font, X., Sánchez, A., and Puntes, V. (2009). Evaluation of the Ecotoxicity of Model Nanoparticles. Chemosphere 75, 850-857. doi:10.1016/j.chemosphere.2009.01.078

Barrena, R., Vargas-García, M. d. C., Capell, G., Barańska, M., Puntes, V., MoralVico, J., et al. (2021). Sustained Effect of Zero-Valent Iron Nanoparticles under Semi-Continuous Anaerobic Digestion of Sewage Sludge: Evolution of
- Nevertheless, worthwile to mention that there is a wide range of nanoparticles concentation, type mode operation and assay conditions that make difficult to the reader to compare and interpret some studies.

\section{DATA AVAILABILITY STATEMENT}

The original contributions presented in the study are included in the article/Supplementary Material, further inquiries can be directed to the corresponding author.

\section{AUTHOR CONTRIBUTIONS}

All the authors contributed to the conception and design of the study. EC wrote the first draft of the manuscript. All authors contributed to manuscript revision, read, and approved the submitted version.

Nanoparticles and Microbial Community Dynamics. Sci. Total Environ. 777, 145969. doi:10.1016/j.scitotenv.2021.145969

Beiki, H., and Keramati, M. (2019). Improvement of Methane Production from Sugar Beet Wastes Using $\mathrm{TiO} 2$ and $\mathrm{Fe} 3 \mathrm{O} 4$ Nanoparticles and Chitosan Micropowder Additives. Appl. Biochem. Biotechnol. 189, 13-25. doi:10.1007/ s12010-019-02987-2

Casals, E., Barrena, R., García, A., González, E., Delgado, L., Busquets-Fité, M., et al. (2014). Programmed Iron Oxide Nanoparticles Disintegration in Anaerobic Digesters Boosts Biogas Production. Small 10, 2801-2808. doi:10.1002/ smll.201303703

Cerrillo, M., Burgos, L., Ruiz, B., Barrena, R., Moral-Vico, J., Font, X., et al. (2021). In-Situ Methane Enrichment in Continuous Anaerobic Digestion of Pig Slurry by Zero-Valent Iron Nanoparticles Addition under Mesophilic and Thermophilic Conditions. Renew. Energ. 180, 372-382. doi:10.1016/ j.renene.2021.08.072

Chen, J. L., Steele, T. W. J., and Stuckey, D. C. (2018a). The Effect of Fe2NiO4 and Fe4NiO4Zn Magnetic Nanoparticles on Anaerobic Digestion Activity. Sci. Total Environ. 642, 276-284. doi:10.1016/ j.scitotenv.2018.05.373

Chen, R., Konishi, Y., and Nomura, T. (2018b). Enhancement of Methane Production by Methanosarcina Barkeri Using Fe 3 O 4 Nanoparticles as Iron Sustained Release Agent. Adv. Powder Technol. 29, 2429-2433. doi:10.1016/j.apt.2018.06.022

Cruz Viggi, C., Rossetti, S., Fazi, S., Paiano, P., Majone, M., and Aulenta, F. (2014). Magnetite Particles Triggering a Faster and More Robust Syntrophic Pathway of Methanogenic Propionate Degradation. Environ. Sci. Technol. 48, 7536-7543. doi:10.1021/es5016789

Dehhaghi, M., Tabatabaei, M., Aghbashlo, M., Kazemi Shariat Panahi, H., and Nizami, A.-S. (2019). A State-Of-The-Art Review on the Application of Nanomaterials for Enhancing Biogas Production. J. Environ. Manage. 251, 109597. doi:10.1016/j.jenvman.2019.109597

Fu, L., Zhou, T., Wang, J., You, L., Lu, Y., Yu, L., et al. (2019). NanoFe3O4 as Solid Electron Shuttles to Accelerate Acetotrophic Methanogenesis by Methanosarcina Barkeri. Front. Microbiol. 10, 1-13. doi:10.3389/ fmicb. 2019.00388

Hassanein, A., Lansing, S., and Tikekar, R. (2019). Impact of Metal Nanoparticles on Biogas Production from Poultry Litter. Bioresour. Technol. 275, 200-206. doi:10.1016/j.biortech.2018.12.048

He, C., Lin, W., Zheng, X., Wang, C., Hu, Z., and Wang, W. (2019). Synergistic Effect of Magnetite and Zero-Valent Iron on Anaerobic Degradation and Methanogenesis of Phenol. Bioresour. Technol. 291, 121874. doi:10.1016/ j.biortech.2019.121874

Im, S., Yun, Y.-M., Song, Y.-C., and Kim, D.-H. (2019). Enhanced Anaerobic Digestion of Glycerol by Promoting DIET Reaction. Biochem. Eng. J. 142, 18-26. doi:10.1016/j.bej.2018.11.006 
Jin, Z., Zhao, Z., and Zhang, Y. (2019). Potential of Direct Interspecies Electron Transfer in Synergetic Enhancement of Methanogenesis and Sulfate Removal in an Up-Flow Anaerobic Sludge Blanket Reactor with Magnetite. Sci. Total Environ. 677, 299-306. doi:10.1016/j.scitotenv.2019.04.372

Khalid, M. J., Zeshan, S., Waqas, A., and Nawaz, I. (2019). Synergistic Effect of Alkaline Pretreatment and Magnetite Nanoparticle Application on Biogas Production from Rice Straw. Bioresour. Technol. 275, 288-296. doi:10.1016/ j.biortech.2018.12.051

Lee, J., Koo, T., Yulisa, A., and Hwang, S. (2019). Magnetite as an Enhancer in Methanogenic Degradation of Volatile Fatty Acids under Ammonia-Stressed Condition. J. Environ. Manage. 241, 418-426. doi:10.1016/ j.jenvman.2019.04.038

Lei, Y., Wei, L., Liu, T., Xiao, Y., Dang, Y., Sun, D., et al. (2018). Magnetite Enhances Anaerobic Digestion and Methanogenesis of Fresh Leachate from a Municipal Solid Waste Incineration Plant. Chem. Eng. J. 348, 992-999. doi:10.1016/j.cej.2018.05.060

Leitão, P., Aulenta, F., Rossetti, S., Nouws, H. P. A., and Danko, A. S. (2018). Impact of Magnetite Nanoparticles on the Syntrophic Dechlorination of 1,2Dichloroethane. Sci. Total Environ. 624, 17-23. doi:10.1016/ j.scitotenv.2017.12.110

Li, S., Cao, Y., Zhao, Z., and Zhang, Y. (2019). Regulating Secretion of Extracellular Polymeric Substances through Dosing Magnetite and Zerovalent Iron Nanoparticles to Affect Anaerobic Digestion Mode. ACS Sustain. Chem. Eng. 7, 9655-9662. doi:10.1021/acssuschemeng.9b01252

Liang, Y.-G., Li, X.-J., Zhang, J., Zhang, L.-G., and Cheng, B. (2017). Effect of Microscale ZVI/Magnetite on Methane Production and Bioavailability of Heavy Metals during Anaerobic Digestion of Diluted Pig Manure. Environ. Sci. Pollut. Res. 24, 12328-12337. doi:10.1007/s11356-017$8832-9$

Liu, C., Tong, Q., Li, Y., Wang, N., Liu, B., and Zhang, X. (2019). Biogas Production and Metal Passivation Analysis during Anaerobic Digestion of Pig Manure: Effects of a Magnetic Fe3O4/FA Composite Supplement. RSC Adv. 9, 4488-4498. doi:10.1039/c8ra09451a

Liu, L., Zhang, T., Wan, H., Chen, Y., Wang, X., Yang, G., et al. (2015). Anaerobic Co-Digestion of Animal Manure and Wheat Straw for Optimized Biogas Production by the Addition of Magnetite and Zeolite. Energ. Convers. Manage. 97, 132-139. doi:10.1016/j.enconman.2015.03.049

Namal, O. O. (2019). Investigation of the Effects of Different Conductive Materials on the Anaerobic Digestion. Int. J. Environ. Sci. Technol. 17, 473-482. doi:10.1007/s13762-019-02498-x

Noonari, A. A., Mahar, R. B., Sahito, A. R., and Brohi, K. M. (2019). Anaerobic CoDigestion of Canola Straw and Banana Plant Wastes with Buffalo Dung: Effect of Fe3O4 Nanoparticles on Methane Yield. Renew. Energ. 133, 1046-1054. doi:10.1016/j.renene.2018.10.113

Peng, H., Zhang, Y., Tan, D., Zhao, Z., Zhao, H., and Quan, X. (2018). Roles of Magnetite and Granular Activated Carbon in Improvement of Anaerobic Sludge Digestion. Bioresour. Technol. 249, 666-672. doi:10.1016/ j.biortech.2017.10.047

Qin, Y., Wang, H., Li, X., Cheng, J. J., and Wu, W. (2017). Improving Methane Yield from Organic Fraction of Municipal Solid Waste (OFMSW) with Magnetic Rice-Straw Biochar. Bioresour. Technol. 245, 1058-1066. doi:10.1016/j.biortech.2017.09.047

Rahman, K. M., Melville, L., Huq, S. M. I., and Khoda, S. K. (2016). Understanding Bioenergy Production and Optimisation at the Nanoscale - A Review. J. Exp. Nanoscience 11, 762-775. doi:10.1080/17458080.2016.1157905

Ren, G., Chen, P., Yu, J., Liu, J., Ye, J., and Zhou, S. (2019). Recyclable Magnetite-Enhanced Electromethanogenesis for Biomethane Production from Wastewater. Water Res. 166, 115095. doi:10.1016/ J.WATRES.2019.115095

Romero-Güiza, M. S., Vila, J., Mata-Alvarez, J., Chimenos, J. M., and Astals, S. (2016). The Role of Additives on Anaerobic Digestion: A Review. Renew. Sustain. Energ. Rev. 58, 1486-1499. doi:10.1016/j.rser.2015.12.094

Song, X., Liu, J., Jiang, Q., Zhang, P., Shao, Y., He, W., et al. (2019). Enhanced Electron Transfer and Methane Production from Low-Strength Wastewater Using a New Granular Activated Carbon Modified with Nano-Fe3O4. Chem. Eng. J. 374, 1344-1352. doi:10.1016/j.cej.2019.05.216

Vecchia, C. D., Mattioli, A., Bolzonella, D., Palma, E., Viggi, C. C., and Aulenta, F. (2016). Impact of Magnetite Nanoparticles
Supplementation on the Anaerobic Digestion of Food Wastes: Batch and Continuous-Flow Investigations. Chem. Eng. Trans. 49, 1-6. doi:10.3303/CET1649001

Wang, C., Liu, Y., Jin, S., Chen, H., Xu, X., Wang, Z., et al. (2019a). Responsiveness Extracellular Electron Transfer (EET) Enhancement of Anaerobic Digestion System during Start-Up and Starvation Recovery Stages via Magnetite Addition. Bioresour. Technol. 272, 162-170. doi:10.1016/j.biortech.2018.10.013

Wang, C., Qiao, W., Chen, H., Xu, X., and Zhu, L. (2019b). A Short-Term Stimulation of Ethanol Enhances the Effect of Magnetite on Anaerobic Digestion. Appl. Microbiol. Biotechnol. 103, 1511-1522. doi:10.1007/s00253018-9531-2

Wang, T., Zhang, D., Dai, L., Chen, Y., and Dai, X. (2016). Effects of Metal Nanoparticles on Methane Production from Waste-Activated Sludge and Microorganism Community Shift in Anaerobic Granular Sludge. Sci. Rep. 6, 1-10. doi:10.1038/srep25857

Wang, T., Zhang, D., Dai, L., Dong, B., and Dai, X. (2018). Magnetite Triggering Enhanced Direct Interspecies Electron Transfer: A Scavenger for the Blockage of Electron Transfer in Anaerobic Digestion of High-Solids Sewage Sludge. Environ. Sci. Technol. 52, 7160-7169. doi:10.1021/acs.est.8b00891

Wang, Y., Ren, G., Zhang, T., Zou, S., Mao, C., and Wang, X. (2017). Effect of Magnetite Powder on Anaerobic Co-Digestion of Pig Manure and Wheat Straw. Waste Manage. 66, 46-52. doi:10.1016/j.wasman.2017.04.031

Xiang, Y., Yang, Z., Zhang, Y., Xu, R., Zheng, Y., Hu, J., et al. (2019). Influence of Nanoscale Zero-Valent Iron and Magnetite Nanoparticles on Anaerobic Digestion Performance and Macrolide, Aminoglycoside, $\beta$-Lactam Resistance Genes Reduction. Bioresour. Technol. 294, 122139. doi:10.1016/ j.biortech.2019.122139

Yamada, C., Kato, S., Ueno, Y., Ishii, M., and Igarashi, Y. (2015). Conductive Iron Oxides Accelerate Thermophilic Methanogenesis from Acetate and Propionate. J. Biosci. Bioeng. 119, 678-682. doi:10.1016/j.jbiosc.2014.11.001

Yang, F., Wang, J., Gu, C., Han, Y., Liu, G.-F., and Lu, H. (2019). Submicron Magnetite-Enhanced Tribromophenol Removal and Methanogenesis under Microaerobic Condition. J. Chem. Technol. Biotechnol. 94, 730-738. doi:10.1002/jctb.5817

Yang, Z., Xu, X., Dai, M., Wang, L., Shi, X., and Guo, R. (2017). Accelerated Ciprofloxacin Biodegradation in the Presence of Magnetite Nanoparticles. Chemosphere 188, 168-173. doi:10.1016/j.chemosphere.2017.08.159

Yang, Z., Xu, X., Guo, R., Fan, X., and Zhao, X. (2015). Accelerated Methanogenesis from Effluents of Hydrogen-Producing Stage in Anaerobic Digestion by Mixed Cultures Enriched with Acetate and Nano-Sized Magnetite Particles. Bioresour. Technol. 190, 132-139. doi:10.1016/j.biortech.2015.04.057

Zaidi, A. A., RuiZhe, F., Shi, Y., Khan, S. Z., and Mushtaq, K. (2018). Nanoparticles Augmentation on Biogas Yield from Microalgal Biomass Anaerobic Digestion. Int. J. Hydrogen Energ. 43, 14202-14213. doi:10.1016/j.ijhydene.2018.05.132

Zhang, J., Lu, T., Wang, Z., Wang, Y., Zhong, H., Shen, P., et al. (2019a). Effects of Magnetite on Anaerobic Digestion of Swine Manure: Attention to Methane Production and Fate of Antibiotic Resistance Genes. Bioresour. Technol. 291 121847. doi:10.1016/j.biortech.2019.121847

Zhang, J., Wang, Z., Lu, T., Liu, J., Wang, Y., Shen, P., et al. (2019b). Response and Mechanisms of the Performance and Fate of Antibiotic Resistance Genes to Nano-Magnetite during Anaerobic Digestion of Swine Manure. J. Hazard. Mater. 366, 192-201. doi:10.1016/j.jhazmat.2018.11.106

Zhang, J., Zhao, W., Zhang, H., Wang, Z., Fan, C., and Zang, L. (2018). Recent Achievements in Enhancing Anaerobic Digestion with Carbon- Based Functional Materials. Bioresour. Technol. 266, 555-567. doi:10.1016/ j.biortech.2018.07.076

Zhang, Y., Yang, Z., Xu, R., Xiang, Y., Jia, M., Hu, J., et al. (2019). Enhanced Mesophilic Anaerobic Digestion of Waste Sludge with the Iron Nanoparticles Addition and Kinetic Analysis. Sci. Total Environ. 683, 124-133. doi:10.1016/ j.scitotenv.2019.05.214

Zhao, Z., Li, Y., Quan, X., and Zhang, Y. (2017). Towards Engineering Application: Potential Mechanism for Enhancing Anaerobic Digestion of Complex Organic Waste with Different Types of Conductive Materials. Water Res. 115, 266-277. doi:10.1016/j.watres.2017.02.067 
Zhao, Z., Li, Y., Yu, Q., and Zhang, Y. (2018a). Ferroferric Oxide Triggered Possible Direct Interspecies Electron Transfer between Syntrophomonas and Methanosaeta to Enhance Waste Activated Sludge Anaerobic Digestion. Bioresour. Technol. 250, 79-85. doi:10.1016/ j.biortech.2017.11.003

Zhao, Z., Zhang, Y., Li, Y., Quan, X., and Zhao, Z. (2018b). Comparing the Mechanisms of ZVI and $\mathrm{Fe} 3 \mathrm{O} 4$ for Promoting Waste-Activated Sludge Digestion. Water Res. 144, 126-133. doi:10.1016/ j.watres.2018.07.028

Conflict of Interest: The authors declare that the research was conducted in the absence of any commercial or financial relationships that could be construed as a potential conflict of interest.
Publisher's Note: All claims expressed in this article are solely those of the authors and do not necessarily represent those of their affiliated organizations, or those of the publisher, the editors and the reviewers. Any product that may be evaluated in this article, orclaim that may be made by its manufacturer, is not guaranteed or endorsed by the publisher.

Copyright $\odot 2021$ Casals, Barrena, Gonzalez, Font, Sánchez and Puntes. This is an open-access article distributed under the terms of the Creative Commons Attribution License (CC BY). The use, distribution or reproduction in other forums is permitted, provided the original author $(s)$ and the copyright owner(s) are credited and that the original publication in this journal is cited, in accordance with accepted academic practice. No use, distribution or reproduction is permitted which does not comply with these terms. 